\title{
OPEN A new mouse model for retinal degeneration due to Fam161a deficiency
}

\author{
Avigail Beryozkin ${ }^{1}$, Chen Matsevich ${ }^{1}$, Alexey Obolensky ${ }^{1}$, Corinne Kostic ${ }^{2}$, Yvan Arsenijevic $^{2}$, \\ Uwe Wolfrum ${ }^{3}$, Eyal Banin ${ }^{1 \bowtie}$ \& Dror Sharon ${ }^{1 凶}$
}

FAM161A mutations are the most common cause of inherited retinal degenerations in Israel. We generated a knockout (KO) mouse model, Fam161a ${ }^{\text {tm1b/tm1b}}$, lacking the major exon \#3 which was replaced by a construct that include LacZ under the expression of the Fam161a promoter. LacZ staining was evident in ganglion cells, inner and outer nuclear layers and inner and outer-segments of photoreceptors in KO mice. No immunofluorescence staining of Fam161a was evident in the KO retina. Visual acuity and electroretinographic (ERG) responses showed a gradual decrease between the ages of 1 and 8 months. Optical coherence tomography (OCT) showed thinning of the whole retina. Hypoautofluorescence and hyperautofluorescence pigments was observed in retinas of older mice. Histological analysis revealed a progressive degeneration of photoreceptors along time and high-resolution transmission electron microscopy (TEM) analysis showed that photoreceptor outer segment disks were disorganized in a perpendicular orientation and outer segment base was wider and shorter than in WT mice. Molecular degenerative markers, such as microglia and CALPAIN-2, appear already in a 1-month old KO retina. These results indicate that a homozygous Fam161a frameshift mutation affects retinal function and causes retinal degeneration. This model will be used for gene therapy treatment in the future.

Retinitis pigmentosa [RP (MIM \#268000)] is the most prevalent hereditary degeneration of the retina in humans, with a prevalence of 1:4500 (in Europe and USA) ${ }^{1-4}$, and 1:2100 in the vicinity of Jerusalem ${ }^{5}$. RP is genetically and clinically heterogeneous, patients in early stages report reduced night vision and narrowing of the visual field, which are caused by death of rod photoreceptors. Subsequently, cone photoreceptors degenerate, leading to loss of central vision, decrease in visual acuity and eventually total blindness. Patients with RP usually have severely diminished or completely absent a-waves on electroretinographic (ERG) testing and bone spicule-like pigmentations (BSPs), attenuation of retinal vessels and a waxy pallor of the optic disc on funduscopy.

Currently, mutations in more than 60 genes were linked to non-syndromic RP, 41 of them were reported to cause autosomal recessive disease (RetNet, https://sph.uth.edu/retnet/), including FAM161A, which was initially identified in Israeli, Palestinian, Indian, and European patients ${ }^{6,7}$.

Clinical analysis of 100 Israeli patients with biallelic FAM161A mutations revealed some unique features including relatively slow degeneration of the photoreceptor layer up to the age of $\sim 30$ and good preservation of the photoreceptor cells in the macula until late age ${ }^{8}$, features which will enable therapeutic intervention (gene therapy, for example) in the future. While the phenotype of FAM161A patients is well described, the exact function of the encoded protein/s and the pathological mechanisms of the disease remain unknown.

Retinal analysis of Fam161a revealed its localization to the base of the photoreceptor connecting cilium, the synaptic regions of the outer and inner plexiform layers and the ganglion cells ${ }^{9,10}$ and takes a part of the cytoskeleton fraction of the mouse photoreceptor sensory cilium complex ${ }^{11,12}$. Different studies showed that Fam161a is part of microtubule-organizing centers, has a role in stabilization of existing microtubules ${ }^{9}$ and in the assembly of the primary cilium in cell cultures ${ }^{10}$. FAM161A binds directly to microtubules and its presence cause an increase in the acetylation of $\alpha$-tubulin and stabilization of microtubules ${ }^{9}$. FAM161 A contains a single highly conserved domain, termed UPF0564, located at the C-terminal region that is predicted to mediate microtubule association, interaction with other UPF0564 containing proteins and allows it to bind to more than 50 other ciliary proteins, such as LCA5 and CEP $290^{9,10}$. In addition, FAM161A has been reported to be a member of the

\footnotetext{
${ }^{1}$ Department of Ophthalmology, Hadassah Medical Center, Faculty of Medicine, The Hebrew University of Jerusalem, 91120 Jerusalem, Israel. ²Department of Ophthalmology, Jules-Gonin Eye Hospital, University of Lausanne, 1004 Lausanne, Switzerland. ${ }^{3}$ Institute for Molecular Physiology, Johannes Gutenberg University, 55128 Mainz, Germany. ${ }^{\circledR}$ email: banine@cc.huji.ac.il; dror.sharon1@mail.huji.ac.il
} 

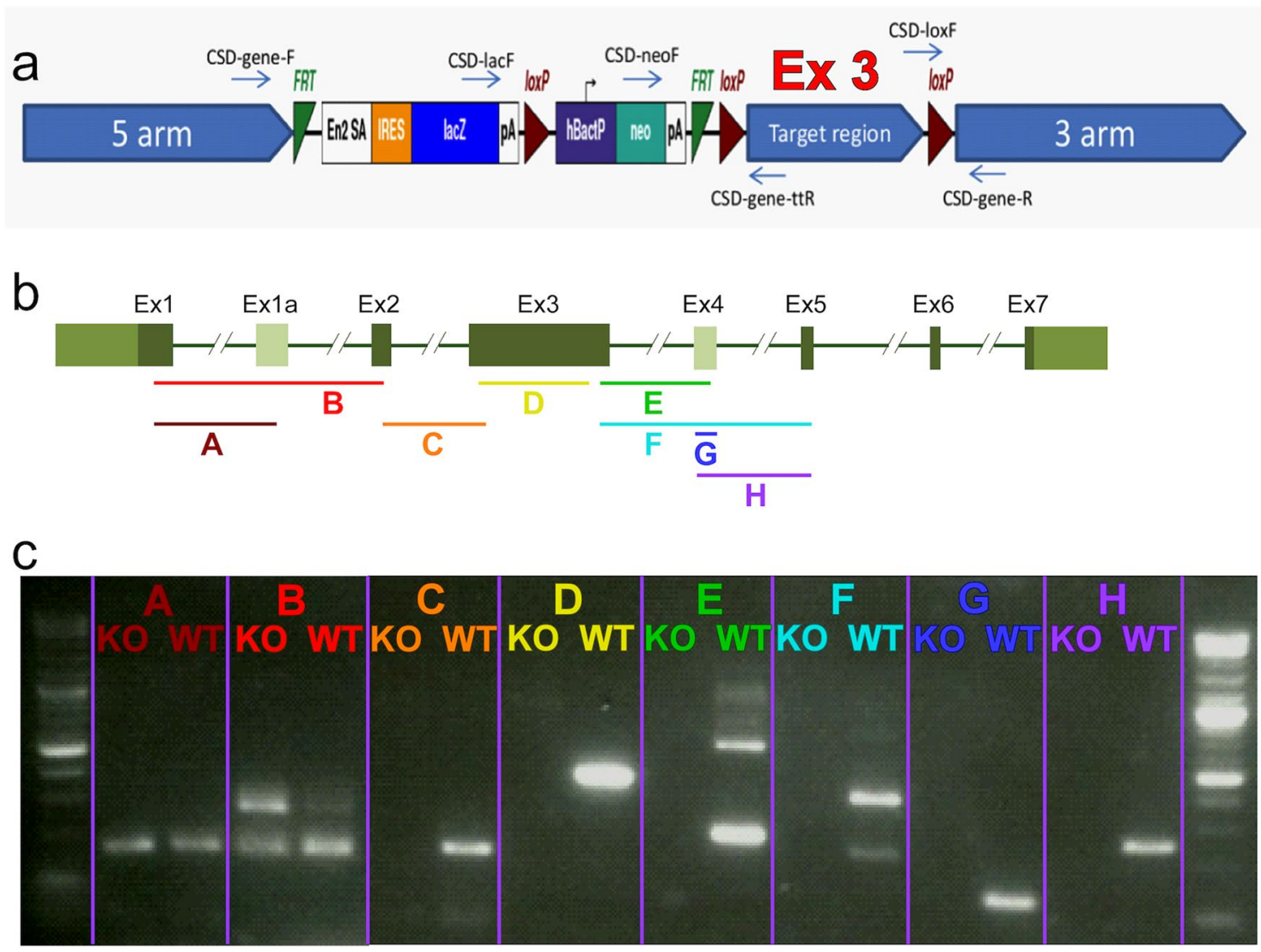

Figure 1. Fam161a knock out cassette and RNA expression in the mouse retina. (a) Schematic representation of the cassette (edited based on https://www.komp.org/ProductSheet.php?cloneID=635102) inserted into the mouse genome, targeting exon \#3 of Fam161a (as provided by the KOMP company). (b) Schematic representation of the Fam161a structure. Dark green are exons that appear in all the transcripts, light green are alternative exons that appear in part of the transcripts. Color fragments represent the predicted RNA products in a specific PCR reaction. (c) RT-PCR products of different fragments of the Fam161a RNA in WT and Fam161 $a^{\text {tm1b/tm1b }}$ mice. Each color represents a different fragment which fits the color on the top panel.

Golgi-centrosomal interactome that is involved in Golgi maintenance, intracellular transport and centrosome organization and to follow the centrosome through all stages of mitosis during cell cycle ${ }^{13}$. Thus, this protein is not limited to ciliary tasks only, but also has some additional cellular functions.

Animal models for retinal degeneration usually provide insights into pathological mechanism of disease progression and assist in designing therapeutic strategies. Up to date several animal models and particular mouse models for retinal diseases have been reported which occurred spontaneously and other models which have induced mutations in known retinal genes ${ }^{14,15}$. Some of these animal models served for gene therapy ${ }^{15-19}$. A mouse model for Fam161a deficiency, created using the GeneTrap system, has previously been reported ${ }^{20}$. Although retinal degeneration was evident in this model, the mutation site was considered "leaky" because it weakly express a truncated form of Fam161a in the inner segment of retinal photoreceptor cells, a situation that does not reflect the mutations identified in human patients that are considered null ${ }^{6,8,21-33}$. This mouse model therefore is less pertinent to study complete FAM161A loss.

In this study we report the generation and characterization of Fam $161 a^{t m 1 b} / t m 1 b-a$ KO mouse model for Fam161a, which exhibits retinal degeneration with autosomal recessive inheritance. We show that mutated mice carry an out-of-frame deletion of the main exon (\#3) in Fam161a producing a short RNA transcript that does not encode the major functional protein domain and is likely to be true null. The disease in our animal model mimics the disease in humans, suggesting that it may be a useful research tool for further disease characterization and gene augmentation therapy.

\section{Results}

Generation of Fam $161 a^{\mathrm{tm} 1 \mathrm{~b} / \mathrm{Tm} 1 \mathrm{~b}}$ mice. We engineered a homozygous mouse line with targeted deletion of exon number 3 in Fam161a $\left(\right.$ Fam161 $\left.a^{\mathrm{tm} 1 \mathrm{~b} / \mathrm{tm} 1 \mathrm{~b}}\right)$ using a selection cassette that contains FRT and LoxP sites (Fig. 1a), which defines the area around exon \#3 from position 23019523 at chromosome 11 to position 23021927 (exon 3 is located between positions 23019999-23021133). The LoxP sites were activated in order to remove the flanked area, and created the following deletion: NC_000077.6 (NM_028672.3): g.23019523_23021927del, as verified using Sanger sequencing of PCR products. 
Fam161a expression in Fam161 ${ }^{\mathrm{tm} 1 \mathrm{~b} / \mathrm{Tm} 1 \mathrm{~b}}$ mouse retinas. Aiming to study the mutation effect at the RNA level, we performed RT-PCR analysis on Fam $161 a^{\mathrm{tm} 1 \mathrm{~b} / \mathrm{tm} 1 \mathrm{~b}}$ and WT retina at the age of 1 month using eight pairs of primers (Fig. 1b, fragments A-H), covering exons $1-5$. We were able to identify RNA expression of the two first fragments (A and B, covering exons 1, 1a, and 2) in WT and Fam161a $a^{\mathrm{tm} 1 \mathrm{~b} / \mathrm{tm} 1 \mathrm{~b}}$ mice approximately at the same level (Fig. 1c). In fragment B, a band that corresponds to the isoform that contains a novel exon \#1a (Supplementary Note) is more intense in mutant RNA comparing to WT. Starting from fragment C and downstream, we were not able to identify any RNA expression in mutated mice, though the expression in WT mice was evident (Fig. 1c). The sequence of all bands was verified by Sanger sequencing.

To determine the expression pattern of Fam161a in the mouse retina without using antibodies, we utilized the LacZ cassette that was inserted into the mouse genome instead of exon 3. LacZ expression was identified mainly in the inner segment but also in the outer segment of photoreceptors and in the outer plexiform layer (Fig. 2a). We observed immunofluorescence staining that is similar but not identical to the one observed by using Fam161a antibodies. The staining we obtained was absent in the Fam161a KO retina (Fig. 2b). The LacZ results confirmed the previous ${ }^{6,7}$ immunohistochemistry staining findings (Fig. 2b) regarding the localization of the Fam161a protein in the mouse retina.

Retinal images of 83 Fam161 $a^{\mathrm{tm} 1 \mathrm{~b} / \mathrm{tm} 1 \mathrm{~b}}$ and $40 \mathrm{WT}$ mice were stained with hematoxylin and eosin and analyzed using the Image-J software (Fig. 2c-e). H\&E staining of retinal sections (Fig. 2c) demonstrated the gradual thinning of the ONL in Fam $161 a^{\mathrm{tm} 1 \mathrm{~b} / \mathrm{tm} 1 \mathrm{~b}}$ retina. Retinal thinning is statistically significant between 1 month-old mutant mice comparing to all other ages, while no statistically significant difference was obtained between 1 month-old WT and mutant mice. When the ONL was studied, a statistically significant difference was obtained among all age groups. Progressive injury of the outer retina and thinning of ONL is observed from 3 months of age, and only sparse photoreceptor nuclei remain at the age of 8 months.

Progressive thinning of the whole retina and ONL occurred in Fam161a $a^{\mathrm{tm} 1 \mathrm{~b} / \mathrm{tm} 1 \mathrm{~b}}$ mice while WT showed stable retinal and ONL thickness over time. We observed thinning of the retina in the Fam $161 a^{\mathrm{tm} 1 \mathrm{~b} / \mathrm{tm} 1 \mathrm{~b}}$ mice groups compared to WT (Fig. $2 \mathrm{~d}$ and Table 1): while mean of total retinal thickness was similar at age of 1 and 6 months in WT mice, a statistically significant decrease was obtained in the Fam $161 a^{\mathrm{tm} 1 \mathrm{~b} / \mathrm{tm} 1 \mathrm{~b}}$ mice along age reaching about $50 \%$ at the age 8 months $(81.15 \mu \mathrm{m}$ compared to 155.83 at the age of 1 month). Furthermore, we identified major and statistically significant thinning of the ONL, which explains the thinning of the retina (Fig. 2e and Table 1).

Visual function of Fam $161 a^{\mathrm{tm} 1 \mathrm{~b} / \mathrm{tm} 1 \mathrm{~b}}$ mice. Visual acuity (VA) in Fam161 $a^{\mathrm{tm} 1 \mathrm{~b} / \mathrm{tm} 1 \mathrm{~b}}$ mice was estimated by OKT test. VA deteriorates over time, while in WT mice VA remains stable through the 8 months of the experiment (Fig. 3a). At the age of 1 month, a small but not statistically significant difference between Fam $161 a^{\text {tm } 1 \mathrm{~b} /}$ tmlb and WT mice was observed, while a significant difference was obtained from the age of 3 months and on ( $\mathrm{p}$-value $<0.001$, marked in ${ }^{\star}$ ). At the age of 8 months Fam $161 a^{\mathrm{tm} 1 \mathrm{~b} / \mathrm{tm} 1 \mathrm{~b}}$ mice are not able to distinguish between light and dark.

Retinal function was assessed in parallel by electroretinography. Scotopic and photopic ERG responses deteriorate over time in Fam $161 a^{\mathrm{tm} 1 \mathrm{~b} / \mathrm{tm} 1 \mathrm{~b}}$ mice, while in WT mice the responses remain stable through 6 months of the experiment (Fig. 3b-c). At 1 month of age, the difference between WT (green line) and Fam161a $a^{\mathrm{tm} 1 \mathrm{~b} / \mathrm{tm} 1 \mathrm{~b}}$ (red line) is already notable. At the age of 6 months, (black line) Fam $161 a^{\mathrm{tm} 1 \mathrm{~b} / \mathrm{tm} 1 \mathrm{~b}}$ mice photoreceptor response to light stimulus is not detected by ERG.

Retinal imaging of Fam161 $a^{\text {tm1b/tm1b }}$ mice. In vivo imaging of Fam $161 a^{\text {tm1b/tm1b }}$ mice by fundus autofluorescence (FAF) revealed narrowing of blood vessels and formation of patchy hypo (black)-as well as hyperautofluorescent (white) spots that developed over time in Fam $161 a^{\mathrm{tm} 1 \mathrm{~b} / \mathrm{tm} 1 \mathrm{~b}}$ mice, indicating widespread retinal degeneration. These changes are most clearly seen at the latest time point (Fig. 4, bottom panel). OCT imaging showed thinning of the outer nuclear layer (ONL) in affected animals over time (marked by yellow lines in Fig. 4). At the age of 6 months the ONL was not detectable at all. WT mouse retina remained at the same thickness even at the age of 6 months (Fig. 4-bottom row).

Fam161 $a^{\mathrm{tm} 1 \mathrm{~b} / \mathrm{tm} 1 \mathrm{~b}}$ photoreceptor structure. TEM analysis of 1-month old WT and Fam161a $a^{\mathrm{tm} 1 \mathrm{~b} / \mathrm{tm} 1 \mathrm{~b}}$ mouse retinas were performed in order to better understand the course of the disease at the cell level. In WT animal, all retinal layers and cells are well organized, densely packed, and have clear directionality. The outer segments are arranged upright, tightly packed and clearly distinguishable from the inner segment (Fig. 5a). In Fam $161 a^{\mathrm{tm} 1 \mathrm{~b} / \mathrm{tm} 1 \mathrm{~b}}$ mouse retina, disorganization is evident along the section and it is difficult to distinguish between different cell regions because cells invade to neighbor ones (Fig. 5b). The outer segments are disorganized, lost their polarity, and spaces are formed between them.

Higher resolution analysis of a single rod photoreceptor from WT retina (Fig. 5c) shows a typical feather shape, the disks of the outer segment are well organized and grow horizontally and parallel to each other, the structures of the connecting cilium are also parallel to each other and on the base of the connecting cilium, basal body and the centriole are evident. Rod photoreceptors from the Fam $161 a^{\mathrm{tm} 1 \mathrm{~b} / \mathrm{tm} 1 \mathrm{~b}}$ mouse retina (Fig. 5d-e), however, show gross abnormalities in cell structure. Some photoreceptors had a very short connecting cilium, the disks of the outer segment are growing vertically out of it, and the inner segment also lost its structure (Fig. 5d). Other photoreceptors show dysmorphic connecting cilium which becomes wider at the end that is closer to the outer segment (Fig. 5e). The disks start to grow from the middle of the connecting cilium and the structures of the connecting cilium are not parallel any more. The inner segment also lost its structure. In all cases photoreceptors lost their feather shape and shortening of the connecting cilium and dysmorphic inner segment and 

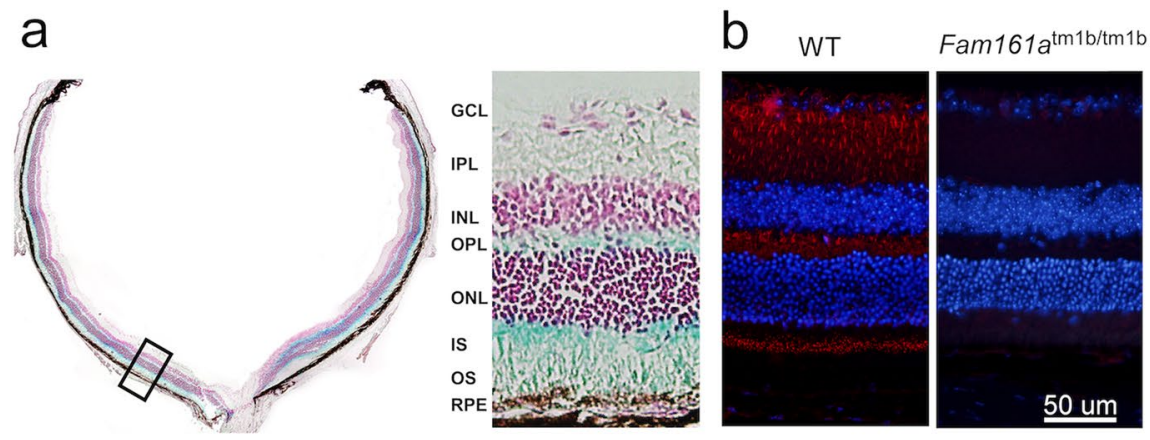

C WT

Fam161 $\mathrm{a}^{\mathrm{tm} 1 \mathrm{~b} / \mathrm{tm} 1 \mathrm{~b}}$

WT

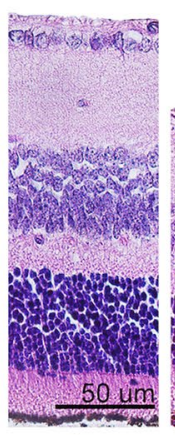

$1 \mathrm{~m}$

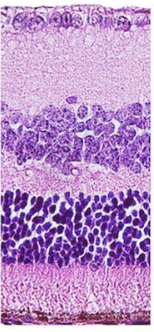

$1 \mathrm{~m}$

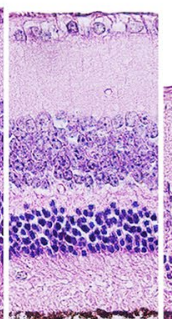

$3 \mathrm{~m}$

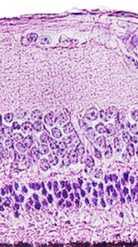

$4.5 \mathrm{~m}$

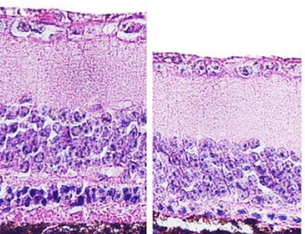

$6 m$

$8 \mathrm{~m}$

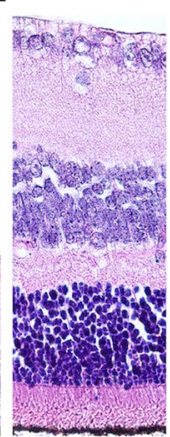

$8 m$
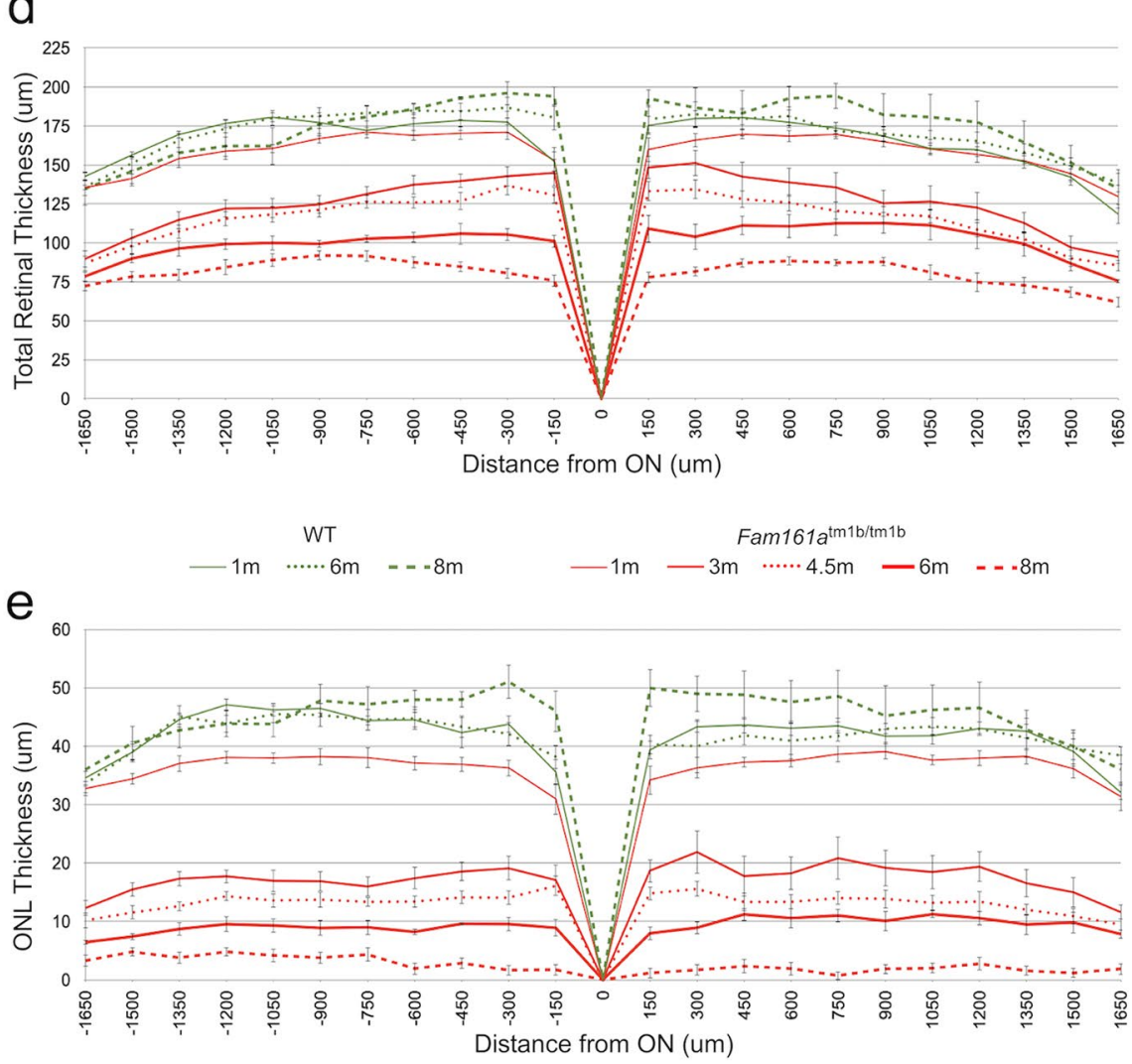

Figure 2. Retinal structure in Fam $161 a^{\mathrm{tm} 1 \mathrm{~b} / \mathrm{tm} 1 \mathrm{~b}}$ and WT mice. (a) LacZ expression in Fam161a $a^{\mathrm{tm} 1 \mathrm{~b} / \mathrm{tm} 1 \mathrm{~b}}$ mouse retina. LacZ cassette was inserted instead of exon 3 of Fam161a, and therefore the cells that express LacZ are the cells that originally expressed Fam 161a. Blue color represents the area where LacZ was able to dismantle $\beta$-gal. Nuclei of different cells are stained in red. A black square (left) represents the region chosen for magnification (right side). (b) Representative IHC images from 1 month old WT and Fam161a ${ }^{\text {tm } 1 \mathrm{~b} / \mathrm{tm} 1 \mathrm{~b}}$ mouse retinas stained with anti-Fam161a antibody. The retina was counterstained with DAPI to define nuclear layers. Original magnification: $\times 20$. Scale bar: $50 \mu \mathrm{m}$. (c) Retinal histology in Fam161 $a^{\mathrm{tm} 1 \mathrm{~b} / \mathrm{tm} 1 \mathrm{~b}}$ and WT mice. Representative images of midperipheral retina stained with hematoxylin and eosin. Original magnification: $\times 40$. Scale bar: $50 \mu \mathrm{m}$. (d) Total retinal thickness in Fam 161 $a^{\mathrm{tm} 1 \mathrm{~b} / \mathrm{tm} 1 \mathrm{~b}}$ and WT mice. (e) ONL thickness in Fam 161 $\mathrm{a}^{\mathrm{tm} 1 \mathrm{~b} / \mathrm{tm} 1 \mathrm{~b}}$ and WT mice. The measurements in d and e panels were done in fragments of $150 \mu \mathrm{m}$ from the optic nerve $(\mathrm{ON})$ towards the nasal $(\mathrm{N})$ and temporal $(\mathrm{T})$ periphery. 


\begin{tabular}{|c|c|c|c|c|c|c|}
\hline Genotype & WT & & Fam161a & nib/tmlb & & \\
\hline Age & 1 month & 6 months & 1 month & 3 months & 6 months & 8 months \\
\hline Total retinal thickness (mean, $\mu \mathrm{m}$ ) [p-value] & 165.49 & 168.88 & \begin{tabular}{|l|}
155.83 \\
{$[0.016]$}
\end{tabular} & \begin{tabular}{|l|}
120.19 \\
{$[<0.001]$} \\
\end{tabular} & $\begin{array}{l}102.01 \\
{[<0.001]}\end{array}$ & \begin{tabular}{|l|}
81.15 \\
{$[<0.001]$}
\end{tabular} \\
\hline ONL thickness (mean, $\mu \mathrm{m}$ ) [p-value] & 46.2 & 41.1 & \begin{tabular}{|l}
35.4 \\
{$[0.0002]$}
\end{tabular} & \begin{tabular}{|l|}
17.03 \\
{$[<0.001]$}
\end{tabular} & \begin{tabular}{|l|}
9.0 \\
{$[<0.001]$}
\end{tabular} & \begin{tabular}{|l|}
2.55 \\
{$[<0.001]$}
\end{tabular} \\
\hline
\end{tabular}

Table 1. Total retinal and outer nuclear layer (ONL) thickness in WT and Fam161 $a^{\mathrm{tm} 1 \mathrm{~b} / \mathrm{tm} 1 \mathrm{~b}}$ mice.
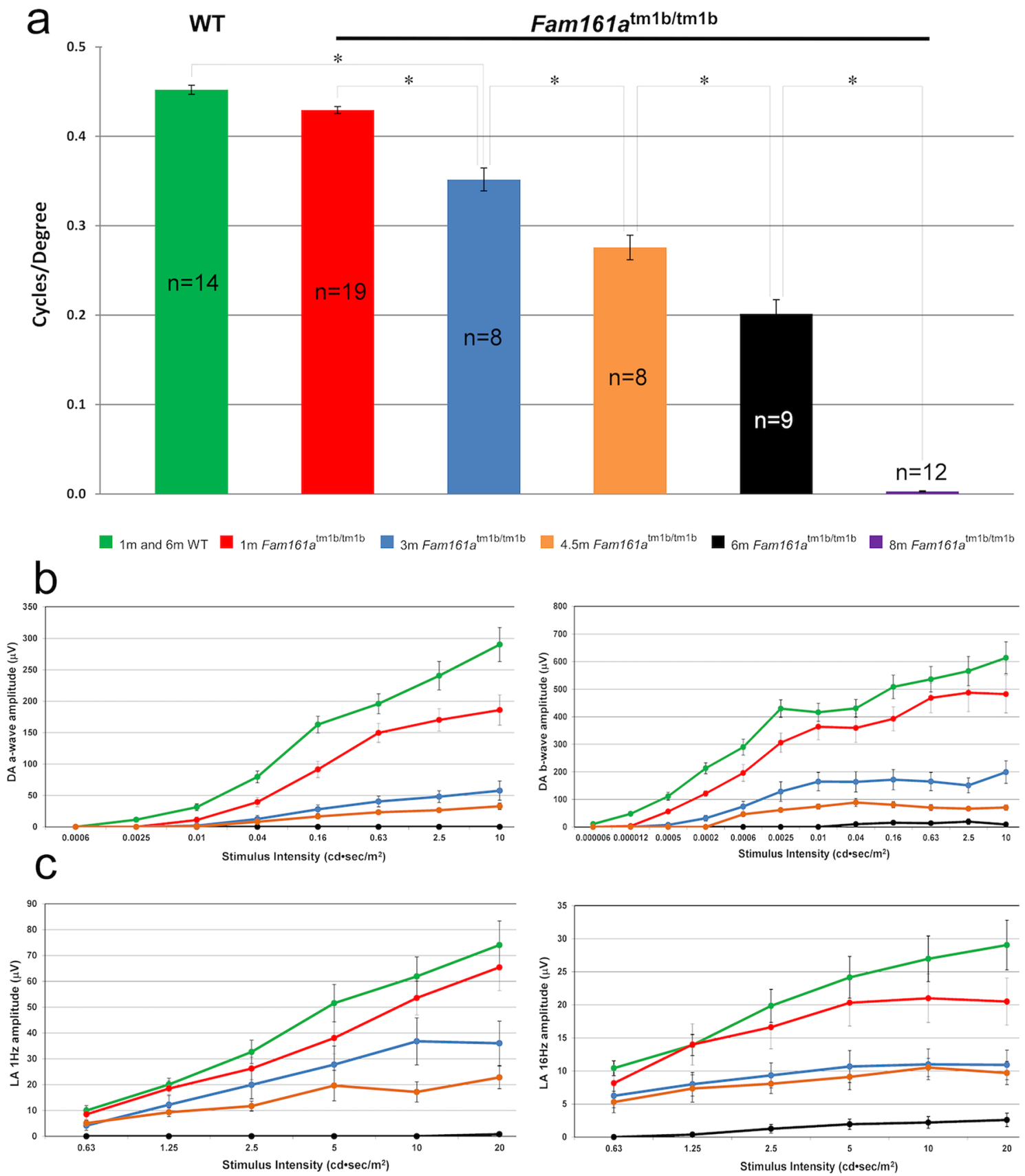

Figure 3. Retinal function in Fam161 $a^{\mathrm{tm} 1 \mathrm{~b} / \mathrm{tm} 1 \mathrm{~b}}$. (a) Visual acuity in WT (average results of 7 mice at the age of 1 months and 7 mice at the age of 8 months) and mutant mice in different ages (represented by the different colors). (b) A-wave and B-wave ERG responses in dark adapted conditions of WT and Fam161 $a^{\mathrm{tm} 1 \mathrm{~b} / \mathrm{tm} 1 \mathrm{~b}}$ mice at different ages. The green line represents WT mice at different ages (average results of 10 mice at the age of 1 months and 9 mice at the age of 8 months). Red, blue, orange and black lines represent mutant mice at ages 1 , 3, 4.5 and 6 months respectively. (c) ERG responses in light-adapted conditions (1 Hz and $16 \mathrm{~Hz}$ stimulus) of WT and Fam161 $a^{\mathrm{tm} 1 \mathrm{~b} / \mathrm{tm} 1 \mathrm{~b}}$ mice at different ages. 


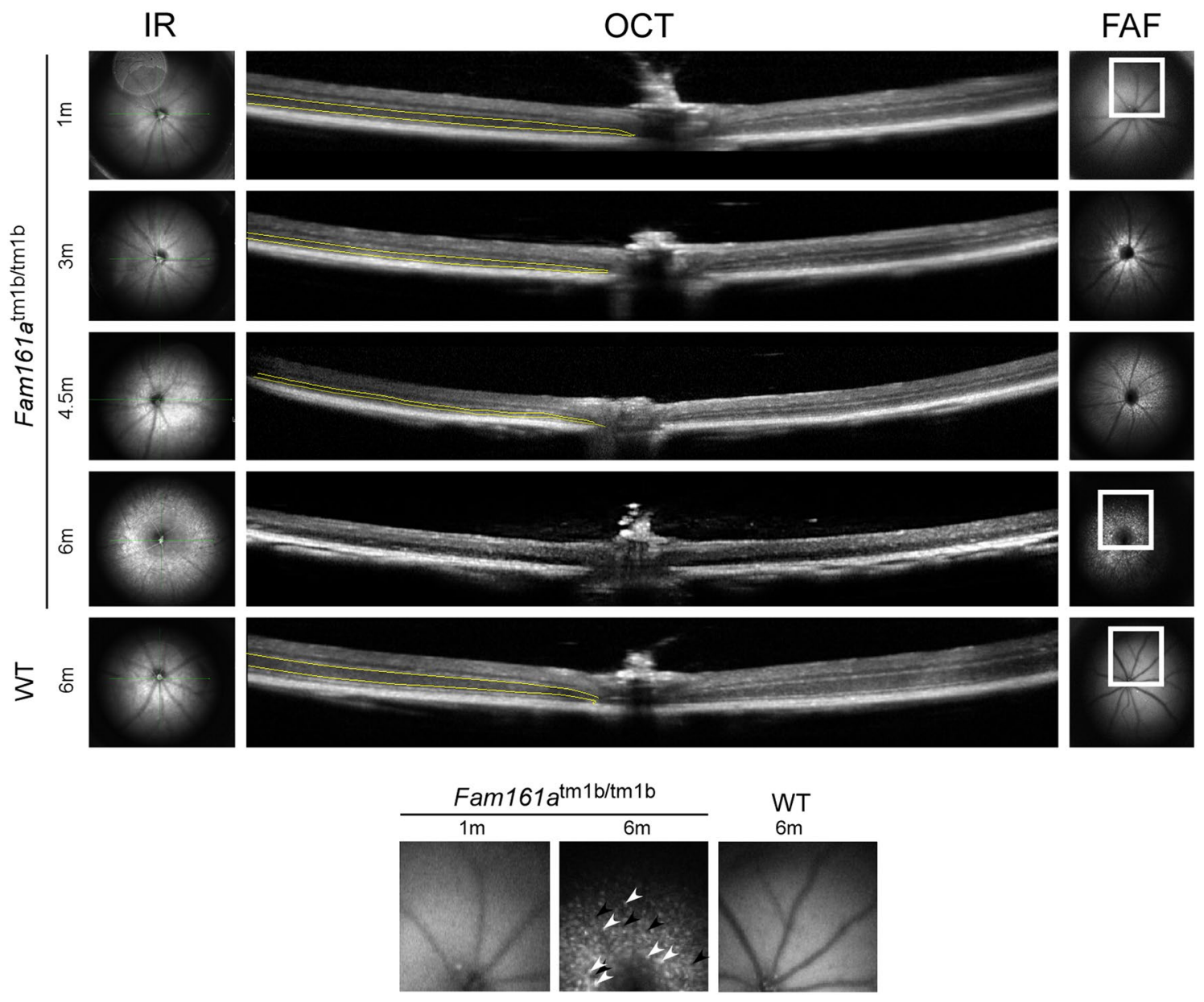

Figure 4. FAF and OCT imaging of Fam $161 a^{\mathrm{tm} 1 \mathrm{~b} / \mathrm{tm} 1 \mathrm{~b}}$ mouse retinas at different ages. A comparison between Fam $161 a^{\mathrm{tm} 1 \mathrm{~b} / \mathrm{tm} 1 \mathrm{~b}}$ mouse retinas at 1, 3, 4.5 and 6 months of age and WT mouse retina at the age of 6 months is presented. The outer nuclear layer which represents the photoreceptors is marked by yellow lines. Enlarged areas are highlighted in squares and are shown at the bottom of the figure. Patchy hypoautofluorescent spots are marked with black arrowheads and hyperautofluorescent spots are marked with white arrowheads.

outer segment are evident. The connecting cilium length is reduced in Fam $161 a^{\mathrm{tm} 1 \mathrm{~b} / \mathrm{tm} 1 \mathrm{~b}}$ photoreceptors (WT: $1.170 \pm 0.11 \mu \mathrm{m} ;$ Fam $161 a^{\mathrm{tm} 1 \mathrm{~b} / \mathrm{tm} 1 \mathrm{~b}}: 0.754 \pm 0.23 \mu \mathrm{m}$; Fig. 5f).

At the age of 1 month, most photoreceptors in the Fam $161 a^{\mathrm{tm} 1 \mathrm{~b} / \mathrm{tm} 1 \mathrm{~b}}$ retina were dysmorphic, but in some photoreceptors we were able to observe the process of degeneration (Fig. 6a-d). We identified Fam $161 a^{\mathrm{tm} 1 \mathrm{~b} / \mathrm{tm} 1 \mathrm{~b}}$ dysmorphic outer segment disks that change orientation, starting from the position that is closer to the inner segment, where they are growing from, whereas in the position that is closer to the RPE (where they are aging and disconnecting from the photoreceptor) the outer segment disks are still in the normal shape (Fig. 6a-b).

Additional interesting observation was seen at the macro level in all mice that were examined at the age of 1 month. In different areas of the retina, photoreceptors at different stages of degeneration were observed, located near each other (Fig. 6e). Minority of the photoreceptors had still correct morphology, while their neighbors showed disrupted and dysmorphic outer segment.

Cellular and molecular degenerative markers in Fam161 $a^{\mathrm{tm} 1 \mathrm{~b} / \mathrm{tm} 1 \mathrm{~b}}$ retina. Microglia have been previously shown to be activated during retinal degeneration in different retinal degenerative processes, including in the Fam 161a gene trap model ${ }^{20}$. In the 1-month-old WT retina, microglia positive for the IBA1A antigen are situated in the INL and present discrete and thin processes (Supplementary Fig. S1). No cells are detected in the ONL at this age, nor later (data not shown). In contrast, in the 1-month old Fam $161 a^{\text {tm } 1 \mathrm{~b} / \mathrm{tm} 1 \mathrm{~b}}$ mouse retina, IBA1A-positive microglia are already detected in the ONL with processes elongating from the INL and invading a large distance in the ONL. At 2 months, the processes are thicker and at 3 months, positive cells accumulated in the ONL with a denser morphology and shorter processes (Supplementary Fig. S1).

Rod degeneration in inherited retinal degeneration is often non-apoptotic and we investigated whether CALPAIN-2, which was recently shown to tightly correlate with rod death events ${ }^{34}$, also highlights the degenerative process of a retinal ciliopathy such as the Fam $161 a^{\mathrm{tm} 1 \mathrm{~b} / \mathrm{tm} 1 \mathrm{~b}}$ mouse. Very rare CALPAIN-2 positive cells were observed in the ONL of WT retina, whereas CALPAIN-2 is markedly present in many cells at the age of 1 month in the KO mouse retina and the number of CALPAIN-2-positive cells decreased with time (Fig. 7a,b). 
When this number is expressed as a function of the number of row nuclei, a linear decrease of the cell death rate is apparent with the increasing age of the Fam161a $a^{\mathrm{tm} 1 \mathrm{~b} / \mathrm{tm} 1 \mathrm{~b}}$ mouse (Fig. 7c).

\section{Discussion}

In this study we characterized retinal degeneration progress in a new Fam161a KO (Fam161a $\left.a^{\mathrm{tm} 1 \mathrm{~b} / \mathrm{tm} 1 \mathrm{~b}}\right)$ mouse model lacking exon 3. Our functional and structural findings indicate that there is a progressive retinal degeneration that starts before the age of 1 month, similar to the previous mouse model $\left(F a m 161 a^{G T / G T}\right)^{20}$. In our model, complete degeneration of photoreceptors cell layer is evident approximately at the age of 8 months, when no ERG or behavioral responses to light stimulus are detected. The degeneration in our mouse model is slightly slower than the previously reported model of Fam $161 a^{20}$ but faster than many other reported models such as $\mathrm{rd} 6, \mathrm{rd} 7 \mathrm{rd} 8$ and $\mathrm{rd} 9^{14}$. In the previously reported GT model, at the age of 3 months, mice had about 3 rows of photoreceptor nuclei and 1 row at the age of 6 months, while in Fam $161 a^{\mathrm{tm} 1 \mathrm{~b} / \mathrm{tm} 1 \mathrm{~b}}$ mouse model we present here, these stages appear about 1-2 months later. The reason for this difference in severity is currently unclear. It might stem from background genetic differences between mouse strains or the truncated form of Fam161a which is expressed in Fam 161 $a^{\mathrm{GT} / \mathrm{GT}}$ mice ${ }^{20}$ might have a negative effect on photoreceptor survival.

The results of the RT-PCR analysis demonstrate that only a short mRNA transcript is produced, including only exons 1, 1a, and 2 while exons 3 (the largest exon that includes most of the disease-causing mutations in humans) and downstream exons are missing. The model we describe here is different from the previously reported GT model, where RNA is produced approximately at the same level as in WT mice ${ }^{20}$. In addition, in the previous model, low amount of truncated protein was identified by immunohistochemistry staining while no protein at all was identified by Western blot analysis, which led to the conclusion that this model may have residual function ${ }^{20}$. In the current model, only a short RNA molecule including exons 1-2 has been identified which does not contain the most important functional domains of the protein ${ }^{10,13}$ and therefore no functional protein is likely to be produced. In addition, immunohsitochemical staining with antibodies against the protein region encoded by exon 3 and 5 (without exon 4) of Fam 161a showed no expression in Fam 161a $a^{\text {tmlb/tmlb }}$ mice, indicating that there is most probably no functional protein. Since the transcript/s produced in Fam161a $a^{\operatorname{tm} 1 b /}$ tmlb mice do not include the main exon (\#3) as well as the end of the open reading frame, we believe that this Fam $161 a^{\mathrm{tm} 1 \mathrm{~b} / \mathrm{tm} 1 \mathrm{~b}}$ mouse is not leaky, and therefore no full-length protein is produced.

LacZ staining demonstrated that the construct that was inserted is likely to be under the control of the Fam161a promoter and expressed in similar but not identical locations where Fam161a has been reported to be expressed, supporting previous immunohistochemical staining results $s^{6,7,9,20}$. While previous and our immunohistochemical staining identified the protein mainly in the photoreceptors, but also in the OPL and less in the IPL, LacZ staining showed expression only in photoreceptors and OPL.

OKT responses were dramatically reduced by more than $50 \%$ in Fam $161 a^{\mathrm{tm} 1 \mathrm{~b} / \mathrm{tm} 1 \mathrm{~b}}$ mice comparing to WT group at the age of 6 months and therefore are correlated with the full-field ERG analysis which revealed progressive deteriorations along time both in scotopic and photopic conditions. The model we present here demonstrates slower reduction of the ERG responses in comparison to Fam $161 a^{\mathrm{GT} / \mathrm{GT}}$ mouse model at the initial disease phase, which exhibits abnormal scotopic ERG responses already at 1 month of age, and almost undetectable responses at 4 months ${ }^{20}$.

Our in vivo imaging analysis, which was performed in Fam $161 a^{\mathrm{tm} 1 \mathrm{~b} / \mathrm{tm} 1 \mathrm{~b}}$ mouse model for the first time, demonstrated an increased number of hyper and hypo auto-fluorescent spots. We assume that the spots might represent accumulation of microglial cells ${ }^{35}$. These spots provide a valuable prediction of wide-spread retinal degeneration as we also see in other mouse model for retinal degeneration ${ }^{14}$ and human patients deficient for FAM161A who suffer from retinal degenerative diseases in the clinic ${ }^{6}$.

In addition, retinal morphometry and measurements revealed that the ONL thickness was reduced from the age of 1 month old to the age of 8 months old by more than $90 \%$ (from 35.4 to $2.55 \mu \mathrm{m}$ ) and total retinal thickness was reduced from the age of 1 month old to the age of 8 months by nearly $50 \%$ (from 155.83 to $81.15 \mu \mathrm{m})$ In Fam 161 $a^{\mathrm{GT} / \mathrm{GT}}$ mouse model only the reduction of the ONL was measured and it was faster than in Fam $161 a^{\mathrm{tm} 1 \mathrm{~b} / \mathrm{tm} 1 \mathrm{~b}}$ model and compatible with the thinning of the retinal layers as they were observed in H\&E staining ${ }^{20}$. Based on our histological analysis, we predict that the most dominant and aggressive loss of photoreceptor cells in the ONL occurred between the ages of 1-4.5 months in Fam $161 a^{\mathrm{tm} 1 \mathrm{~b} / \mathrm{tm} 1 \mathrm{~b}}$ mice. Regarding the oldest group, only sparse photoreceptor nuclei remained at the age of 8 months, which probably are barely detectable by functional tests. We assume that most of the nuclei we observe at the age of 8 months belong to cells that are not functional anymore and hence we are not able to detect any responses in the VA or ERG tests. In other ages, we observed that the functional tests (VA and ERG) are in-line with the structural ones (OCT, FAF and histological measurements).

The results of the TEM analysis that we performed support those reported in the Fam $161 a^{\mathrm{GT} / \mathrm{GT}}$ mouse model regarding the shape of the cilia and the photoreceptors. In both models photoreceptor outer segment disks were disorganized in a perpendicular orientation. The outer segment base was wider and shorter than in WT mice. This indicates that Fam161a participates in disk morphogenesis at the base of the outer segment as found in other RP models with defective disk formation ${ }^{36}$. In addition, we observed different morphology of photoreceptors in the same mouse at the age of 1 month, while several photoreceptors showed disrupted and dysmorphic discs, other photoreceptors in the same observed area seems to have normal morphologic structure at the observed time point. Those results indicate that near cells that undergo degeneration (and may not be cured even at this early timepoint), one can find cells with normal structure which did not begin the degeneration process yet. Those remaining functional cells probably can be rescued by gene therapy or other intervention.

In addition, we observed diverse arrangements of the membrane disk stacks in one and the same outer segment (e.g. Fig. 6) which is in line with findings in other rd models ${ }^{37}$. Almost nothing is known about the 
Figure 5. TEM (Transmission electron microscopy) sections of $\mathrm{WT}$ and Fam161a $a^{\mathrm{tm} 1 \mathrm{~b} / \mathrm{tm} 1 \mathrm{~b}}$ retina. (a) Representative retina of WT at 1 month. (b) Representative retina of Fam $161 a^{\text {tmlb/tm1b }}$ at 1 month. The two solid lines indicate the extension of the RPE cells. The dashed lines indicate the apical surface of the epithelium from which the microvilli-like extensions extend towards the photoreceptor outer segments. Black asterisk indicate engulfed disk stacks released from outer segments. RPE-Retinal pigment epithelium, OS-Outer segment, IS-Inner segment. Scale bars: $10 \mu \mathrm{m}$. (c,d) Photoreceptor morphology of 1 month-old WT (c) and Fam161a ${ }^{\mathrm{tm} 1 \mathrm{~b} /}$ tmlb (d) mice. A schematic drawing of the cell is presented on the top right on panel c. CC-connecting cilium (marked in black line), BB-basal body, Ce-adjacent centriole. Scale bars: $1 \mu \mathrm{m}$. Note that in the Fam161a $a^{\text {tm1b/tm1b }}$ photoreceptor outer segment disks are disorganized in a perpendicular orientation and the CC is shortened (marked in black line). (e) Photoreceptor morphology of a 1-month-old Fam161a $a^{\mathrm{tm} 1 \mathrm{~b} / \mathrm{tm} 1 \mathrm{~b}}$ mouse. Outer segment base is widened and microtubules spread in their upper part (double headed arrow). Outer segment disks are growing from the middle of the CC (arrowheads). A schematic drawing of the cell is presented on the top right. Scale bars: $1 \mu \mathrm{m}$. (f) Connecting cilium length analysis. Comparative analysis of WT CC length and Fam 161 $a^{\mathrm{tm} 1 \mathrm{~b} / \mathrm{tm} 1 \mathrm{~b}} \mathrm{CC}$ length $\left({ }^{*} \mathrm{P}<0.005\right.$, error bars represent $\left.\mathrm{SD}\right)$.

physiological or molecular basis of this phenomenon. One reason may be that the renewal of the outer segment disks does not occur in a continuous temporal sequence. At the base of the outer segment, new membrane disks are formed, which are mainly stacked in a period of $1-2 \mathrm{~h}$ after the light is switched on ${ }^{38}$ and at that time disk neogenesis is likely faster than at other times. However, there are also indications that not only the speed of disk morphogenesis, but also the molecular composition of the disks along the outer segment may periodically change. More recent, still controversial discussed data indicates that rhodopsin and peripherin-2 are incorporated into the disk stacks under different physiologic conditions, preferentially in dark or light, respectively ${ }^{36,39}$. Although we currently do not know at which period Fam161a participates at the of disk neogenesis it is conceivable that Fam 161a's absence may differential affect disk stacking under different physiologic conditions in a periodic manner.

The heterogeneity of photoreceptor alteration was also observed at the molecular level, with sporadic appearance of the CALPAIN-2 protein in photoreceptors. CALPAINS were shown to be a good indicator of cell death in different forms of inherited retinal degenerations $s^{34,40}$. Because certain CALPAIN inhibitors have shown to delay photoreceptor degeneration in $R d 1$ retinal explants ${ }^{41}$, the rare observation of CALPAIN-2 positive cells in the Fam $161 a^{\text {tm1b/tm1b }}$ model and the linear decrease of cell death rate with aging also suggest that many photoreceptors can be rescued by gene therapy or a neuroprotective approach. However, the marked invasion of microglia in the ONL at the age of 3 months rather suggests an accentuated deterioration of the photoreceptors, which may render more difficult therapeutic applications.

Our results indicate a functional role of Fam161a in the retina, specifically in the photoreceptors. Conclusively, the decrease in all parameters that was noted in Fam $161 a^{\mathrm{tm} 1 \mathrm{~b} / \mathrm{tm} 1 \mathrm{~b}}$ mice during the period of the experiment, showed both that the functional and structural degenerations are less aggressive than those observed in some other genetically-determined retinal degeneration mouse models such as $\mathrm{rd} 1, \mathrm{rd} 4$ and $\mathrm{rd} 10 \mathrm{mice}{ }^{14,42,43}$ and may better resemble the course of RP in humans. Currently, gene augmentation therapy is being examined in this model, as a possible first step to future application of such treatment in human patients with RP caused by FAM161A biallelic mutations.

\section{Methods}

Experiments were conducted in compliance with the ARVO Statement for the Use of Animals in Ophthalmic and Vision Research and were approved by the Hebrew University animal ethics committee.

Generation of Fam161a KO mouse. Mice were generated by Knockout Mouse Project (KOMP) Repository. Promoter-driven selection cassette that contains FRT and LoxP sites and a reporter gene LacZ (Fig. 1a) was

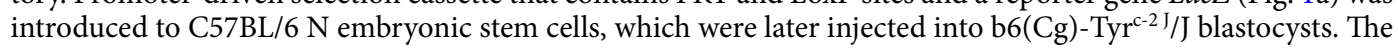
resulting chimeras were bred with $\mathrm{C} 57 \mathrm{BL} / 6 \mathrm{~J}$ mice in order to receive heterozygous mice for the non-activated construct (Fam 161 $\left.\mathrm{a}^{\mathrm{tmla}(\mathrm{KOMP}) W t s i}\right)$. These mice were shipped to our animal facility for further breeding and analyses. Activation of the cassette was performed by crossbreeding heterozygous mice with B6.C-Tg(Pgk1-cre)1Lni/ CrsJ mice (JAX stock \#020811) to receive mice with LacZ instead of exon 3 of Fam161a (Fam161a ${ }^{\text {tmlb(KOMP)Wtsi }}$ ). This activation results in a short RNA transcript which does not contain the major functional protein domain and is likely to be true null. Heterozygous Fam161 $a^{\text {tm1b/WT }}$ mice were generated on a C57BL/6 N background and intercrossed to establish homozygous male and female cohorts for initial phenotypic screening. Fam 161a $a^{\mathrm{tm} 1 \mathrm{~b} / \mathrm{WT}}$ founders were screened for known mutations in Crb1 $(\mathrm{rd} 8)^{44}$, Rpe $5(\mathrm{rd} 12)^{45}$, Gnat2 $^{46}$ and Pde6b $(\mathrm{rd} 10)^{42}(\mathrm{rd} 1)^{43}$ (Primers sequences in Supplementary Table S1). The rd1 and the rd8 mutations, that is common in $6 \mathrm{~N} \mathrm{strain}{ }^{43,47}$, were identified in these mice, and they were crossed with wild-type C57BL/6 J to establish mutant mice free of the confounding rd1 and rd8 mutations. Ten generations of Fam $161 a^{\mathrm{tm} 1 \mathrm{~b} / \mathrm{WT}}$ were crossed with C57BL/6 J mice to establish a strain that has clear and identical background. A research colony was bread crossing heterozygotes to produce homozygous mutants and wild-type control littermates for this study.

Animals. Animals were maintained at the animal facility of the Hebrew University-Hadassah medical center, Ein Kerem campus, Jerusalem, Israel, and kept under specific pathogen free and 12-h light/dark conditions. General microbial examinations were performed routinely by the animal research facility staff. The weight, development, growth and behavior of the knockout animals was also routinely checked and appeared to be normal. 

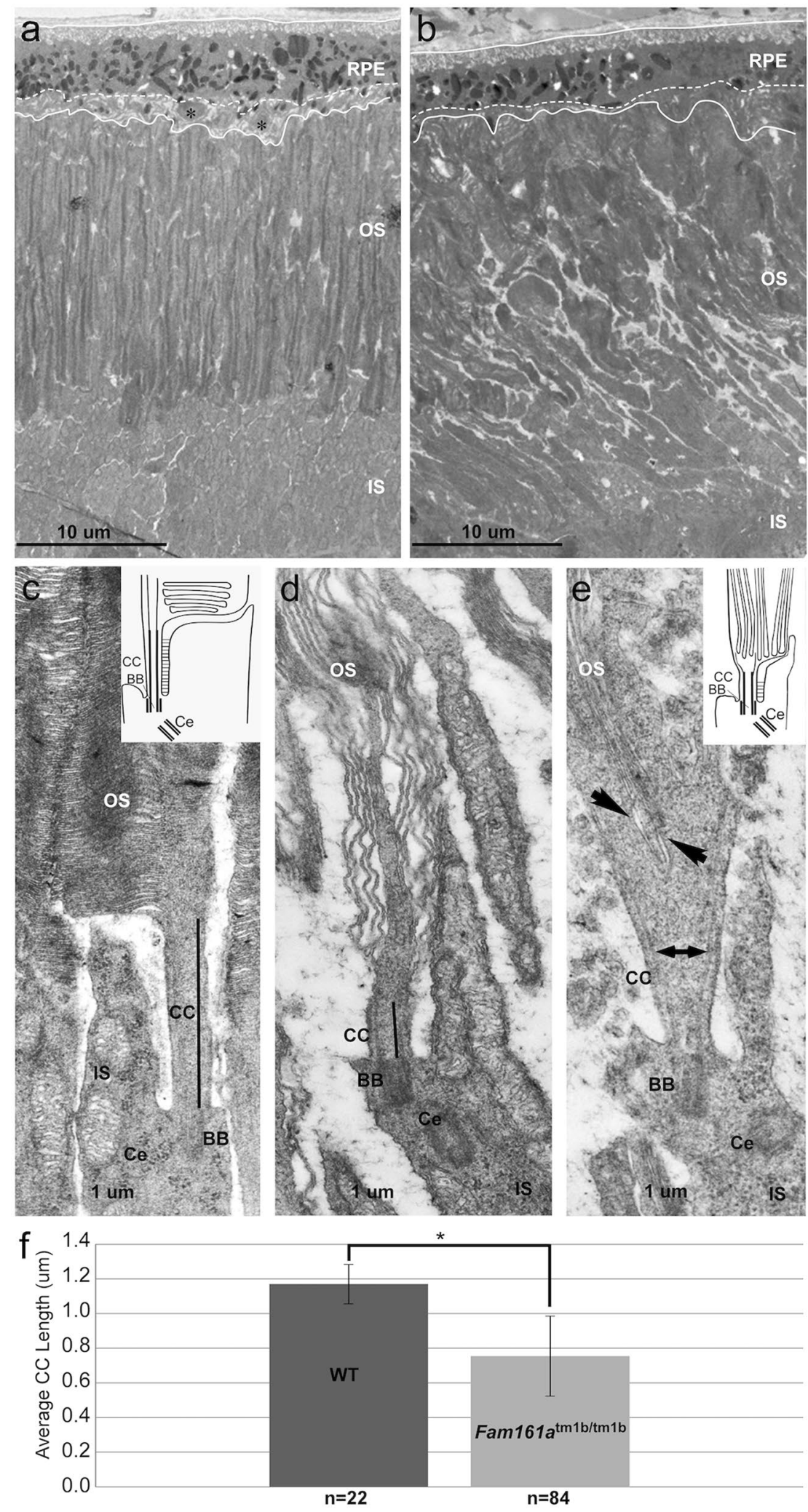

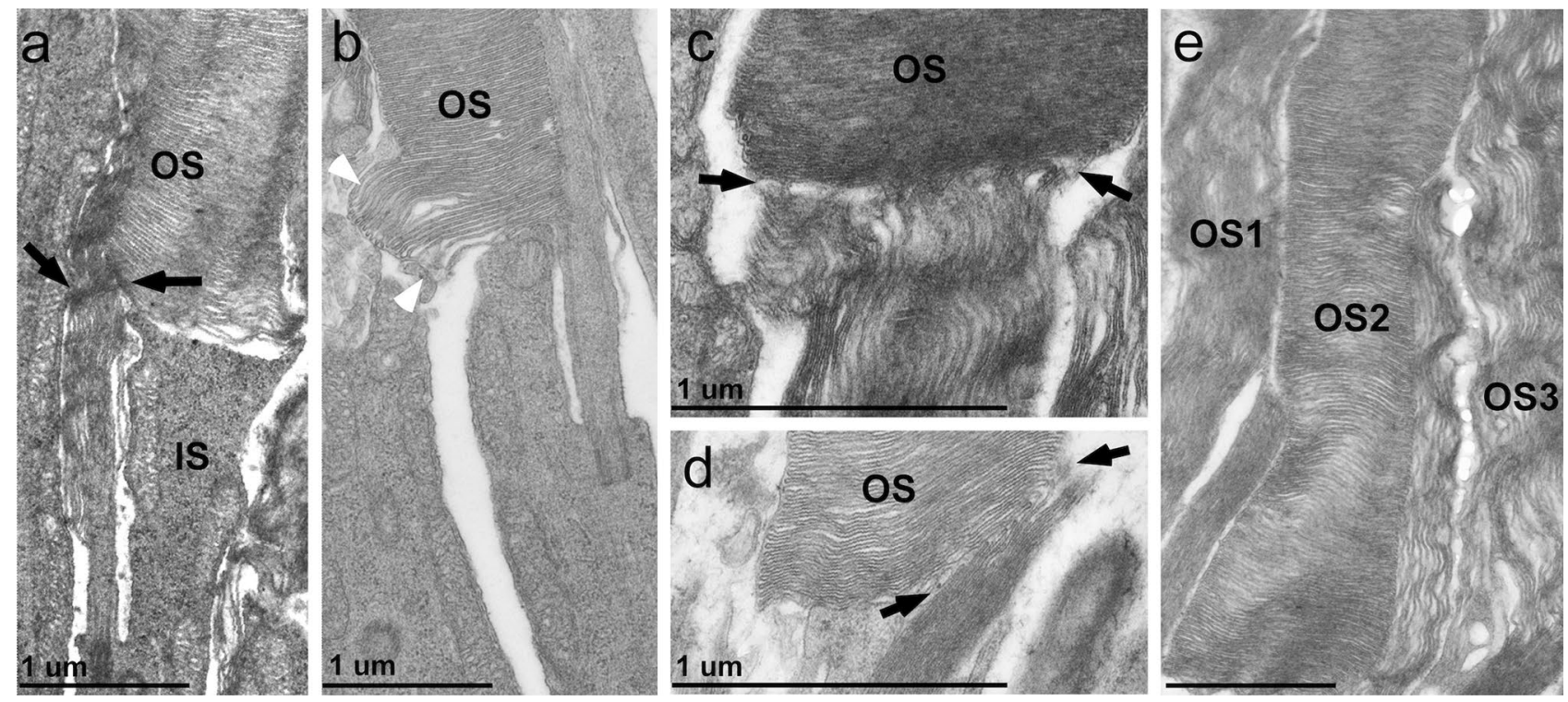

Figure 6. High-resolution TEM analysis of Fam161 $a^{\mathrm{tm} 1 \mathrm{~b} / \mathrm{tm} 1 \mathrm{~b}}$ retina. a single photoreceptor cell from 1-monthold Fam $161 a^{\mathrm{tm} 1 \mathrm{~b} / \mathrm{tm} 1 \mathrm{~b}}$ mouse representing different processes. (a) New discs with different orientation are marked in black arrows. Scale bar: 1 um. (b) Overgrow of disks is marked by white arrowheads. Scale bar: 1 um. (c,d) Zoom-in into the exact location where the orientation of the discs changes (marked in black arrows). (e) Different morphology in the same retina at the age of 1 month is observed. Three different outer segments are shown (OS1, OS2, OS3), and one of them (OS2) shows correct morphology.

Retinal development and progression of retinal degeneration was studied at the ages of 1, 3, 4.5, 6 and 8 months. Mice were anesthetized by intraperitoneal injections of a mixture of $0.85 \mu$ Ketamine (Bedford Laboratories, Bedford, $\mathrm{OH}$ ) and $0.15 \mu \mathrm{l}$ Xylazine (VMD, Arendonk, Belgium), diluted with saline 1:10 and injected with doses suitable to their body weight $(1 \mu \mathrm{l} / \mathrm{g})$. Pupils were dilated with $1 \%$ tropicamide and $2.5 \%$ phenylephrine, local anesthetic drops were administered (benoxinate $\mathrm{HCl}, 0.4 \%$; all ocular drops from Fisher Pharmaceuticals, Tel-Aviv, Israel), and eyes were lubricated with methylcellulose prior to electroretinography (ERG), fundus photography and optical coherence tomography (OCT). Before sacrifice, animals were anesthetized by over-dose of Ketamine and Xylazine followed by cervical dislocation.

Genotyping. DNA was extracted from mouse ear punches using $180 \mu \mathrm{l}$ of $50 \mathrm{mM} \mathrm{NaOH}$ to $5-10 \mathrm{mg}$ of mouse ear sample and incubated for $10 \mathrm{~min}$ at $95^{\circ} \mathrm{C}$. Extract was neutralized by adding $20 \mu \mathrm{l}$ of $1 \mathrm{M}$ Tris-HCL (pH 8.0). Genotyping was performed by using KAPA Mouse Genotyping Kit (KAPA Biosystems), genotyping primers targeted the WT allele, LacZ insert, exon 3 region are reported in Supplementary Table S1.

RNA isolation and RT-PCR analysis. RNA was extracted from mouse retinas using TRI Reagent (T9424, Sigma-Aldrich, Rehovot, Israel). RNA was converted to cDNA using Verso cDNA Kit (AB-1453/B, Thermo Scientific). RT-PCR was performed with $50 \mathrm{ng}$ cDNA to amplify intron-spanning fragments between all Fam161a exons. Primers of the reactions are shown in Supplementary Table S1.

Optokinetic tracking (OKT) response. Visual acuity was measured using an optokinetic testing apparatus (OptoMotry; Cerebral Mechanics, Inc., Lethbridge, AB, Canada) by recording the tracking response (optokinetic reflex) to a rotating visual stimulus displayed on four LCD panels surrounding the mouse. Visual acuity was measured at $100 \%$ contrast in $n=8-19$ mice per age group.

Electroretinography. Full field ERG was performed in anesthetized animals ( $n=8-19$ per age group) after overnight dark adaptation using a Ganzfeld dome and a computerized system (Espion E2, Diagnosys LLC, Littleton, MA), as previously described ${ }^{48}$. Briefly, pupils were dilated and gold-wire active electrodes were placed on the central cornea. A reference electrode was placed on the tongue and a needle ground electrode was placed intramuscularly in the hip area. Dark-adapted rod and mixed cone-rod as well as light-adapted $16 \mathrm{~Hz}$ cone flicker responses to a series of white flashes of increasing intensities $\left(0.00008-9.6 \mathrm{~cd} \mathrm{~s} / \mathrm{m}^{2}\right)$ were recorded. All ERG responses were filtered at $0.3-500 \mathrm{~Hz}$, and signal averaging was applied.

Optical coherence tomography, fundus auto-fluorescence and fundus photography. Retinal structure was studied in vivo by optical coherence tomography (OCT), fundus auto-fluorescence (FAF) imaging and fundus photographs were taken (SPECTRALIS, Heidelberg). The procedures were performed in anesthetized animals with dilated pupils and lubricated eyes as mentioned earlier. At least 8 eyes from 8 different mice were examined per age group. 

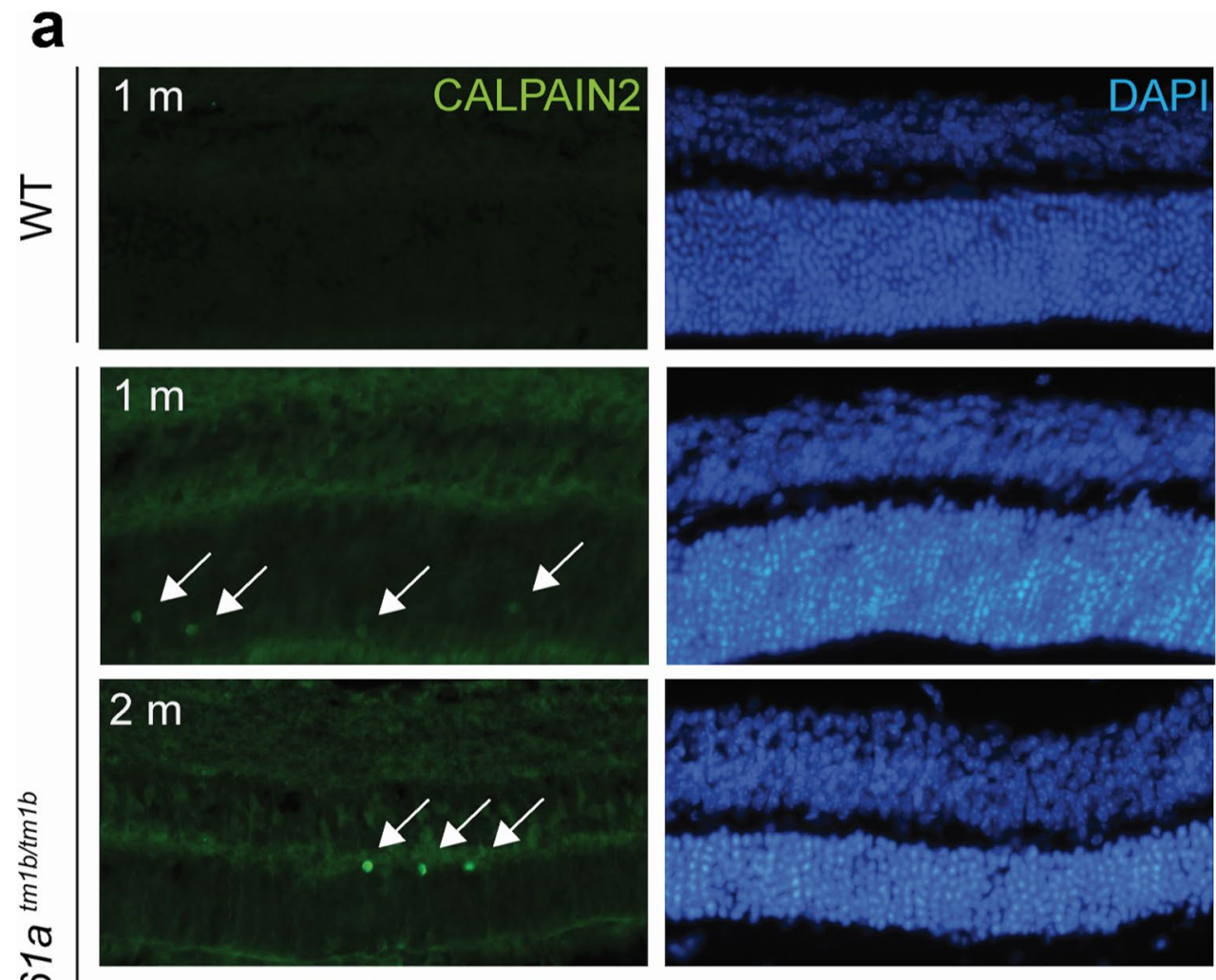

$\frac{0}{\frac{1}{\sigma}}$
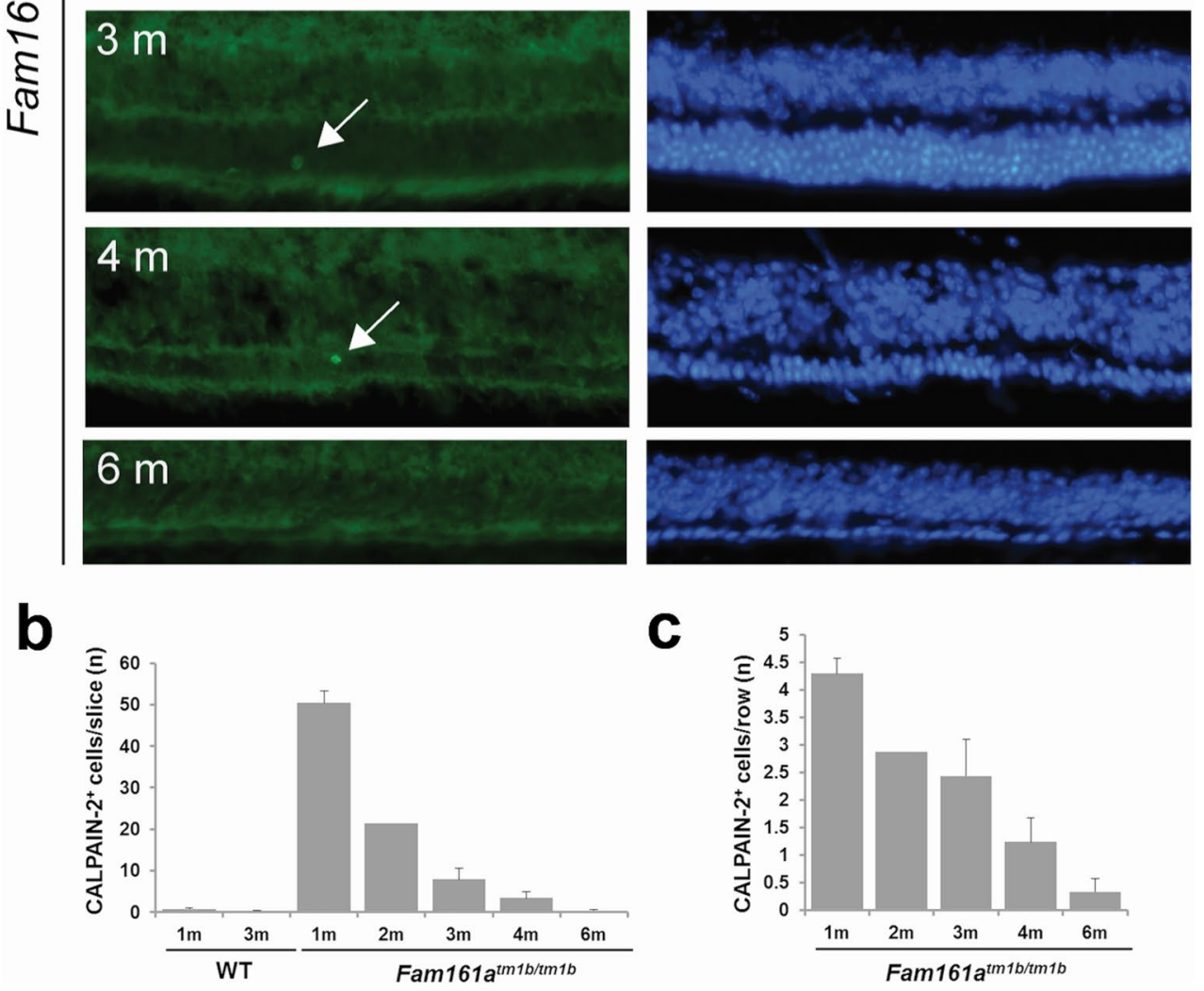

Figure 7. CALPAIN-2 is more present during the early stages of retinal degeneration. (a) CALPAIN-2 (in green, arrows) is present in the ONL of Fam $161 a^{\mathrm{tm} 1 \mathrm{~b} / \mathrm{tm} 1 \mathrm{~b}}$ mouse all along the degenerative process, but the enzyme is almost absent in the WT retina (bottom). (b) The quantification of the absolute number of CALPAIN-2-positive cells shows that cell death is more prominent at 1 month. (c) The rate of the degeneration, evidenced by the number of CALPAIN-2-positive cells per row of photoreceptor, linearly declined with time. $1 \mathrm{~m}$ : 1 month. $\mathrm{n}=3$ for all time points, with the exception of 2 month old mice $(n=2)$. 
Histology and immunohistochemistry (IHC). Eyes were enucleated, fixated in Davidson solution for $8 \mathrm{~h}$ at $4{ }^{\circ} \mathrm{C}$, and moved to $70 \%$ ethanol over-night at $4{ }^{\circ} \mathrm{C}$. Eyes were incubated in a $80->90->100->100 \%$ ethanol gradient in room temperature for $30 \mathrm{~min}$ per each concentration, placed for $15 \mathrm{~min}$ in ethanol 100\%:Xylene (1:1) solution in room temperature and washed twice with xylene $100 \%$ for $20 \mathrm{~min}$ each wash. Samples were incubated in paraffin (Paraplast Plus, Leica biosystems) at $58{ }^{\circ} \mathrm{C}$ for 3 times, each incubation lasted $40 \mathrm{~min}$, later they were embedded in paraplast, and serially cut at $5 \mu \mathrm{m}$ thickness sections through the center of the optic nerve. For immunohistochemistry, standard immunohistological analysis protocol for paraffin section was carried out, as previously described ${ }^{49}$, commercial buffer (ImmunoRetriever $20 \times$ with citrate $\mathrm{pH} 6.62$, Bio Sb) and commercial antibody (rabbit anti-Fam161a, 1:500, HPA032119, Sigma-Aldrich) were used, recognizing an epitope in a sequence encoded by exon 3 and 5 corresponding to short isoform in which exon 4 is skipped). For descriptive histology and quantitative analysis, sections were stained with hematoxylin and eosin (H\&E) following a standard protocol. Each retina was divided to sections of $150 \mu \mathrm{m}$ from the optic nerve towards the nasal and temporal periphery, and thickness of each retinal layer was measured separately once. Then results from the corresponding retinal areas were averaged and a statistical analysis was performed using t-test (significance of $\mathrm{p}<0.05$ ).

For immunohistochemistry, commercial antibodies were used (anti-IBA1, 1:600, \#019-19,741, WAKO and anti-CALPAIN-2, 1:200, ab39165, Abcam) to characterize the process of cell death at different ages.

X-Gal staining. Eyes were enucleated from Fam $161 a^{\mathrm{tm} 1 \mathrm{~b} / \mathrm{tm} 1 \mathrm{~b}}$ and WT mice at the age of 1 month and then fixed in $4 \%$ paraformaldehyde for $20 \mathrm{~min}$ at room temperature. Cornea and lens were removed, eyecup were cryoprotected in a $10->20->30 \%$ sucrose gradient at $4{ }^{\circ} \mathrm{C}$ for at least $1 \mathrm{~h}$ per each concentration. Eyecup were embedded in optimum cutting temperature medium (Sakura Finetek USA, Torrance, CA, USA) frozen in dry ice and 2-methylbutane slurry, and sectioned at $10 \mu \mathrm{m}$ onto Superfrost Plus (Thermo Fisher) slides with a cryostat (Leica CM1950, Leica, Wetzlar, Hesse, Germany). Slides were washed with PBS and stained for X-gal with $\beta$-Galactosidase Reporter Gene Staining Kit (Sigma-Aldrich, Rehovot, Israel) followed by PBS washing and nuclear fast red staining (Vector Laboratories, Burlingame, CA, USA) according to the protocols supplied by the companies. After an additional PBS wash, slides were coverslipped with Vectamount (Vector Laboratories, Burlingame, CA, USA) and imaged.

Statistical analysis. For all histological quantifications, at least $8 \mathrm{Fam} 161 \mathrm{a}^{\mathrm{tm} 1 \mathrm{~b} / \mathrm{tm} 1 \mathrm{~b}}$ mice were imaged for each age and in addition $8 \mathrm{WT}$ mice at the age of 1, 6 and 8 months. Measurements were combined to determine the average per each group. For CALPAIN-2-positive cell quantification, $n=3$ per age and 3 retina slices at the proximity of the optic nerve were counted per animal. For visual acuity and histology, pairwise analyses were performed by using t-test, and p-value of 0.05 or less was considered as statistically significant results.

Imaging. All observations and photography were performed using an Olympus BX41 microscope equipped with a DP70 digital camera. Image processing and quantification were performed using Adobe Photoshop CS2 and Image-J softwares.

Fixation for conventional electron microscopy. Eyes were enucleated and fixed in $2.5 \%$ glutaraldehyde in $0.1 \mathrm{M}$ cacodylate buffer ( $\mathrm{pH} \mathrm{7.4)}$ and $0.1 \mathrm{M}$ sucrose for $30 \mathrm{~min}$ in room temperature. Cornea and lens were removed and the eye cups were incubated in the same mixture for an additional $1.5 \mathrm{~h}$. Eye cups were washed 5 times with $0.1 \mathrm{M}$ cacodylate buffer containing $0.1 \mathrm{M}$ sucrose for $30 \mathrm{~min}$. Later, eye cups were fixed with $2 \% \mathrm{OsO}_{4}$ in $0.1 \mathrm{M}$ cacodylate buffer with $0.1 \mathrm{M}$ sucrose for $1 \mathrm{~h}$ at room temperature. Samples were washed in water and dehydrated in ascending ethanol concentration (2 times per concentration, $10 \mathrm{~min}$ each) 30-> 50-> 70-> 80-> 96-> 100\% ethanol. Samples were embedded in Renlam M-1 restin (Serva Electroporesis, Heidelberg, Germany ${ }^{20}$.

Ultrathin sections were made by using Reichert Ultracut S ultramicrotome (Leica), collected on Formvarcoated copper grids and counterstained with $2 \%$ uranyl acetate in $50 \%$ ethanol and aqueous $2 \%$ lead citrate. The sections were analyzed in a Tecnai 12 BioTwin transmission electron microscope (FEI, Eindhoven, The Netherlands), as previously described ${ }^{20}$. Images were obtained with a CCD camera (charge-coupled-device camera, SIS MegaView3, Surface imaging system, Herzogenrath, Germany) and processed with Adobe Photoshop CS2 and Image-J softwares.

\section{Data availability}

The datasets generated and/or analyzed in the current study are available from the corresponding author upon reasonable request.

Received: 25 August 2020; Accepted: 4 January 2021

Published online: 21 January 2021

\section{References}

1. Rosenberg, T. Epidemiology of hereditary ocular disorders. Developments in ophthalmology vol. 37 (2003).

2. Bundey, S. \& Crews, S. J. A study of retinitis pigmentosa in the City of Birmingham. I. Prevalence. J. Med. Genet. 21, (1984).

3. Peterlin, B. et al. Prevalence of retinitis pigmentosa in Slovenia. Clin. Genet. 42, (1992).

4. Bunker, C. H., Berson, E. L., Bromley, W. C., Hayes, R. P. \& Roderick, T. H. Prevalence of retinitis pigmentosa in maine. Am. J. Ophthalmol. 97, (1984). 
5. Sharon, D. \& Banin, E. Nonsyndromic retinitis pigmentosa is highly prevalent in the Jerusalem region with a high frequency of founder mutations. Mol. Vis. 21, (2015).

6. Bandah-Rozenfeld, D. et al. Homozygosity mapping reveals null mutations in FAM161 A as a cause of autosomal-recessive retinitis pigmentosa. Am. J. Hum. Genet. 87, (2010).

7. Langmann, T. et al. Nonsense mutations in FAM161A cause RP28-associated ecessive retinitis pigmentosa. Am. J. Hum. Genet. 87, (2010).

8. Beryozkin, A. et al. Unique combination of clinical features in a large cohort of 100 patients with retinitis pigmentosa caused by FAM161A mutations. Sci. Rep. https://doi.org/10.1038/s41598-020-72028-0 (2020).

9. Zach, F. et al. The retinitis pigmentosa 28 protein FAM161A is a novel ciliary protein involved in intermolecular protein interaction and microtubule association. Hum. Mol. Genet. 21, (2012).

10. Di gioia, S. A. et al. FAM161a, associated with retinitis pigmentosa, is a component of the cilia-basal body complex and interacts with proteins involved in ciliopathies. Hum. Mol. Genet. (2012). https://doi.org/10.1093/hmg/dds368.

11. Liu, Q. et al. The proteome of the mouse photoreceptor sensory cilium complex. Mol. Cell. Proteomics 6 (2007).

12. Jakobsen, L. et al. Novel asymmetrically localizing components of human centrosomes identified by complementary proteomics methods. EMBO J. 30, (2011).

13. Di Gioia, S. A. et al. Interactome analysis reveals that FAM161A, deficient in recessive retinitis pigmentosa, is a component of the Golgi-centrosomal network. Hum. Mol. Genet. https://doi.org/10.1093/hmg/ddv085 (2015).

14. Chang, B. et al. Retinal degeneration mutants in the mouse. Vision Res. https://doi.org/10.1016/S0042-6989(01)00146-8 (2002).

15. Veleri, S. et al. Biology and therapy of inherited retinal degenerative disease: insights from mouse models. DMM Disease Models Mech https://doi.org/10.1242/dmm.017913 (2015).

16. Maeda, A. \& Maeda, T. Modeling retinal diseases using genetic approaches in mice. in Methods in Molecular Biology (2018). https ://doi.org/10.1007/978-1-4939-7720-8_3.

17. Hassall, M. M., Barnard, A. R. \& Maclaren, R. E. Gene therapy for color blindness. Yale J. Biol. Med. https://doi.org/10.1056/nejmc ibr0908643 (2017).

18. Auricchio, A., Smith, A. J. \& Ali, R. R. The future looks brighter after 25 years of retinal gene therapy. Hum. Gene Ther. https://doi. org/10.1089/hum.2017.164 (2017).

19. Al-Saikhan, F. I. The gene therapy revolution in ophthalmology. Saudi J. Ophthalmol. https://doi.org/10.1016/j.sjopt.2013.02.001 (2013).

20. Karlstetter, M. et al. Disruption of the retinitis pigmentosa 28 gene Fam161a in mice affects photoreceptor ciliary structure and leads to progressive retinal degeneration. Hum. Mol. Genet. https://doi.org/10.1093/hmg/ddu242 (2014).

21. Jespersgaard, C. et al. Molecular genetic analysis using targeted NGS analysis of 677 individuals with retinal dystrophy. Sci. Rep. https://doi.org/10.1038/s41598-018-38007-2 (2019).

22. Venturini, G. et al. Molecular genetics of FAM161A in north american patients with early-onset retinitis pigmentosa. PLoS ONE https://doi.org/10.1371/journal.pone.0092479 (2014).

23. Glöckle, N. et al. Panel-based next generation sequencing as a reliable and efficient technique to detect mutations in unselected patients with retinal dystrophies. Eur. J. Hum. Genet. https://doi.org/10.1038/ejhg.2013.72 (2014).

24. Maranhao, B. et al. Investigating the molecular basis of retinal degeneration in a familial cohort of pakistani decent by exome sequencing. PLoS ONE https://doi.org/10.1371/journal.pone.0136561 (2015).

25. Zhou, Y. et al. Whole-exome sequencing reveals a novel frameshift mutation in the FAM161A gene causing autosomal recessive retinitis pigmentosa in the Indian population. J. Hum. Genet. https://doi.org/10.1038/jhg.2015.92 (2015).

26. Langmann, T. et al. Nonsense mutations in FAM161A cause RP28-associated ecessive retinitis pigmentosa. Am. J. Hum. Genet. https://doi.org/10.1016/j.ajhg.2010.07.018 (2010).

27. Van Schil, K. et al. A nonsense mutation in FAM161A is a recurrent founder allele in dutch and belgian individuals with autosomal recessive retinitis pigmentosa. Investig. Ophthalmol. Vis. Sci. https://doi.org/10.1167/iovs.15-17920 (2015).

28. Carss, K. et al. Comprehensive rare variant analysis via whole-genome sequencing to determine the molecular pathology of inherited retinal disease. Am. J. Hum. Genet. https://doi.org/10.1016/j.ajhg.2016.12.003 (2017).

29. Duncan, J. L. et al. Ocular phenotype of a family with FAM161A-associated retinal degeneration. Ophthalmic Genet. https://doi. org $/ 10.3109 / 13816810.2014 .929716(2016)$

30. Zobor, D., Balousha, G., Baumann, B. \& Wissinger, B. Homozygosity mapping reveals new nonsense mutation in the FAM161A gene causing autosomal recessive retinitis pigmentosa in a Palestinian family. Mol. Vis. (2014).

31. Rose, A. M. et al. Diverse clinical phenotypes associated with a nonsense mutation in FAM161A. Eye https://doi.org/10.1038/ eye.2015.93 (2015)

32. Ellingford, J. M. et al. Molecular findings from 537 individuals with inherited retinal disease. J. Med. Genet. https://doi.org/10.1136/ jmedgenet-2016-103837 (2016).

33. Wang, J. et al. Dependable and efficient clinical utility of target capture-based deep sequencing in molecular diagnosis of retinitis pigmentosa. Investig. Ophthalmol. Vis. Sci. https://doi.org/10.1167/iovs.14-14936 (2014).

34. Power, M. J. et al. Systematic spatiotemporal mapping reveals divergent cell death pathways in three mouse models of hereditary retinal degeneration. J. Comp. Neurol. https://doi.org/10.1002/cne.24807 (2020).

35. Raoul, W. et al. Lipid-bloated subretinal microglial cells are at the origin of drusen appearance in CX3CR1-deficient mice. Ophthalmic Res. https://doi.org/10.1159/000119860 (2008).

36. May-Simera, H., Nagel-Wolfrum, K. \& Wolfrum, U. Cilia-the sensory antennae in the eye. Prog. Retinal Eye Res. https://doi. org/10.1016/j.preteyeres.2017.05.001 (2017).

37. Allon, G. et al. PRCD is concentrated at the base of photoreceptor outer segments and is involved in outer segment disc formation. Hum. Mol. Genet. https://doi.org/10.1093/hmg/ddz248 (2019).

38. Young, R. W. The renewal of photoreceptor cell outer segments. J. Cell Biol. https://doi.org/10.1083/jcb.33.1.61 (1967).

39. Hsu, Y. C., Chuang, J. Z. \& Sung, C. H. Light regulates the ciliary protein transport and outer segment disc renewal of mammalian photoreceptors. Dev. Cell https://doi.org/10.1016/j.devcel.2015.01.027 (2015).

40. Arango-Gonzalez, B. et al. Identification of a common non-apoptotic cell death mechanism in hereditary retinal degeneration. PLoS ONE https://doi.org/10.1371/journal.pone.0112142 (2014).

41. Paquet-Durand, F. et al. Photoreceptor rescue and toxicity induced by different calpain inhibitors. J. Neurochem. https://doi.org/ 10.1111/j.1471-4159.2010.06983.x (2010).

42. Chang, B. et al. Two mouse retinal degenerations caused by missense mutations in the $\beta$-subunit of rod cGMP phosphodiesterase gene. Vision Res. https://doi.org/10.1016/j.visres.2006.11.020 (2007).

43. Giménez, E. \& Montoliu, L. A simple polymerase chain reaction assay for genotyping the retinal degeneration mutation (Pdebrd1) in FVB/N-derived transgenic mice. Lab. Anim. https://doi.org/10.1258/0023677011911525 (2001).

44. Mehalow, A. K. et al. CRB1 is essential for external limiting membrane integrity and photoreceptor morphogenesis in the mammalian retina. Hum. Mol. Genet. https://doi.org/10.1093/hmg/ddg232 (2003).

45. Pang, J. J. et al. Retinal degeneration 12 (rd12): A new, spontaneously arising mouse model for human Leber congenital amaurosis (LCA). Mol. Vis. (2005).

46. Chang, B. et al. Cone photoreceptor function loss-3, a novel mouse model of achromatopsia due to a mutation in Gnat2. Investig. Ophthalmol. Vis. Sci. https://doi.org/10.1167/iovs.05-1468 (2006). 
47. Mattapallil, M. J. et al. The Rd8 mutation of the Crb1 gene is present in vendor lines of C57BL/6N mice and embryonic stem cells, and confounds ocular induced mutant phenotypes. Invest. Ophthalmol. Vis. Sci. https://doi.org/10.1167/iovs.12-9662 (2012).

48. Chowers, G. et al. Course of sodium iodate-induced retinal degeneration in albino and pigmented mice. Investig. Ophthalmol. Vis. Sci. https://doi.org/10.1167/iovs.16-21255 (2017).

49. Banin, E. et al. Retinal incorporation and differentiation of neural precursors derived from human embryonic stem cells. Stem Cells https://doi.org/10.1634/stemcells.2005-0009 (2006).

\section{Acknowledgements}

The authors would like to thank Alaa Abu-Diab, Ayat Khalailah, Elisabeth Sehn, Ophélie Müller and Yaël Alves for technical assistance.

\section{Author contributions}

A.B., Y.A., U.W., E.B., D.S. conceived and design the study; A.B., C.M., A.O., C.K. collected the data; A.B., C.M., A.O., C.K., Y.A., U.W. performed the analysis and the interpretations; Y.A., U.W., E.B., D.S. obtained funding. All authors reviewed the manuscript drafts and contributed corrections, amendments and their expertise.

\section{Funding}

This study was supported by the Swiss National Foundation (Sinergia Grant CRSII3_141814), the Foundation Fighting Blindness (FFB; Grant No. PPA-0717-0719-RAD to UW), the Swiss National Foundation (Grant \#31003A 169492) and the Israeli Science Foundation (Grant 1147/18 to DS). The funding organizations had no role in the design or conduct of this research.

\section{Competing interests}

The authors declare no competing interests.

\section{Additional information}

Supplementary Information The online version contains supplementary material available at https://doi. org/10.1038/s41598-021-81414-1.

Correspondence and requests for materials should be addressed to E.B. or D.S.

Reprints and permissions information is available at www.nature.com/reprints.

Publisher's note Springer Nature remains neutral with regard to jurisdictional claims in published maps and institutional affiliations.

Open Access This article is licensed under a Creative Commons Attribution 4.0 International License, which permits use, sharing, adaptation, distribution and reproduction in any medium or format, as long as you give appropriate credit to the original author(s) and the source, provide a link to the Creative Commons licence, and indicate if changes were made. The images or other third party material in this article are included in the article's Creative Commons licence, unless indicated otherwise in a credit line to the material. If material is not included in the article's Creative Commons licence and your intended use is not permitted by statutory regulation or exceeds the permitted use, you will need to obtain permission directly from the copyright holder. To view a copy of this licence, visit http://creativecommons.org/licenses/by/4.0/.

(C) The Author(s) 2021 